\title{
Article \\ Effects of Low-Intensity Resistance Exercise with Slow Movement and Tonic Force Generation on Short-Term Glycemic Variability in Healthy Subjects: A Randomized Controlled Study
}

\author{
Takuro Shoji ${ }^{1, *(\mathbb{D})}$, Hidetaka Hamasaki ${ }^{2, *} \mathbb{D}$, Akiko Kawaguchi ${ }^{3}$, Yoko Waragai ${ }^{3}$ and Hidekatsu Yanai $^{3}$ \\ 1 Department of Rehabilitation Medicine, National Center for Global Health and Medicine Kohnodai Hospital, \\ Ichikawa-shi, Chiba 272-8516, Japan \\ 2 Hamasaki Clinic, Kagoshima-shi, Kagoshima 890-0046, Japan \\ 3 Department of Internal Medicine, National Center for Global Health and Medicine Kohnodai Hospital, \\ Ichikawa-shi, Chiba 272-8516, Japan; akko817@hotmail.co.jp (A.K.); pooh_3_0412@yahoo.co.jp (Y.W.); \\ dyanai@hospk.ncgm.go.jp (H.Y.) \\ * Correspondence: pt.shoji@hospk.ncgm.go.jp (T.S.); h-hamasaki@umin.ac.jp (H.H.); \\ Tel.: +81-047-372-3501 (T.S.); +81-099-250-3535 (H.H.)
}

Citation: Shoji, T.; Hamasaki, H.; Kawaguchi, A.; Waragai, Y.; Yanai, $\mathrm{H}$. Effects of Low-Intensity Resistance Exercise with Slow Movement and Tonic Force Generation on Short-Term Glycemic Variability in Healthy Subjects: A Randomized Controlled Study. Appl. Sci. 2021, 11, 1536. https://doi.org/10.3390/app11041536

Academic Editor: Gregory Barshtein Received: 29 December 2020

Accepted: 4 February 2021

Published: 8 February 2021

Publisher's Note: MDPI stays neutral with regard to jurisdictional claims in published maps and institutional affiliations.

Copyright: (C) 2021 by the authors. Licensee MDPI, Basel, Switzerland. This article is an open access article distributed under the terms and conditions of the Creative Commons Attribution (CC BY) license (https:/ / creativecommons.org/licenses/by/ $4.0 /)$.

\begin{abstract}
Resistance exercise improves daily glycemic control. Low-intensity resistance exercise with slow movements and tonic force generation (LST) is a resistance exercise protocol that can increase skeletal muscle mass and strength without considerable physical burden; however, its effect on glycemic variability is unknown. The aim of this study was to investigate the effect of LST on short-term glycemic variability, expressed as the M-value, in healthy individuals. We recruited 20 healthy subjects (mean age: $27.9 \pm 3.9$ years) with normal glucose tolerance, and subjects were randomly assigned to the control $(n=10)$ or LST $(n=10)$ groups. Subjects in the LST group performed the resistance exercise with $40-50 \%$ of the one-repetition maximum for $40 \mathrm{~min}$. All subjects wore a subcutaneous continuous glucose monitoring system and a triaxial accelerometer, and their daily glycemic variability and physical activity were measured. One hour after the intervention, in the LST group, the variability of blood glucose levels was significantly decreased compared to the control group (M-values in the LST group: pre $3.5 \pm 6.2$, post $2.7 \pm 2.7, p=0.575$; M-values in the control group: pre $0.4 \pm 0.7$, post $2.7 \pm 2.0, p=0.017$ ). However, there were no differences in total physical activity and daily glycemic control between groups. The findings of this study suggest that LST improves short-term glycemic variability in healthy subjects.
\end{abstract}

Keywords: low-intensity resistance exercise with slow movement and tonic force generation; short-term glycemic variability; healthy subjects

\section{Introduction}

High glycemic variability (GV) induces oxidative stress and inflammation [1], and previous studies have shown that GV is associated with the progression of vascular complications such as neuropathy, retinopathy, and cognitive impairment [2-4] in patients with diabetes. GV is also associated with the development of atherosclerosis due to vascular endothelial dysfunction [5]. Hanefeld et al. [6] reported that the relative risks of developing cardiovascular disease (CVD) $(-35 \%)$ and myocardial infarction $(-64 \%)$ can be reduced by improving post-prandial hyperglycemia in patients with type 2 diabetes; thus, it is crucial to improve GV to reduce the occurrence of CVD. In addition, post-prandial glucose fluctuations specifically induce oxidative stress compared to sustained chronic hyperglycemia [1] Improving GV is important for the prevention of atherosclerosis-related disease in healthy individuals, as well as vascular complications in patients with diabetes.

Recently, a continuous glucose monitoring system (CGMS) was developed that can measure subcutaneous interstitial glucose levels [7]. Current evidence suggests that not 
only is long-term glycemic control important for the management of diabetes, but shortterm GV also has an impact [1]. Yardley et al. [8] showed that resistance exercises more effectively reduce the incidence of glycemia, with smaller fluctuations, than aerobic exercise in patients with type 1 diabetes. Cruz et al. [9] also showed that low-intensity resistance exercise improves hyperglycemia and daily glycemic control in female patients with type 2 diabetes. These two studies suggest that resistance exercise, even at a low intensity, is effective for improving GV. Generally, the intensity required for resistance exercise to improve skeletal muscle mass and strength is not less than $65 \%$ of the one-repetition maximum (1-RM) [10]; however, moderate- to high-intensity resistance exercise might be harmful to the cardiovascular system of physically weak older individuals due to the increase in systolic blood pressure [11,12]. Low-intensity resistance exercise with slow movements and tonic force generation (LST) has beneficial effects on skeletal muscle mass and strength, although the intensity is only $30-50 \%$ of that of the 1-RM $[13,14]$. Watanabe et al. [15] reported that LST significantly increases muscle mass and strength in older adults. Kanda et al. reported that LST leads to improvements in ambulatory function and lower-limb muscle strength in frail elderly patients [16].

Moreover, the increases in blood pressure during exercise caused by Valsalva maneuvers [17] are very limited in LST; thus, it is safe for individuals with arteriosclerotic disease. Recently, Hamasaki et al. [18] reported that 12 weeks of LST training had beneficial effects on body composition, lipid profile, and glycemic control in patients with type 2 diabetes.

However, to date, there are no studies investigating the effect of LST on GV. If performing LST is beneficial for GV in healthy subjects, it will also be useful for patients with diabetes who have reduced muscle strength and impaired physical function [19]. The aim of this study was to investigate whether LST can improve GV in healthy subjects.

\section{Materials and Methods}

\subsection{Study Subjects}

We recruited 20 healthy subjects between 20 and 40 years of age who consented to the disclosure of their health examination results. We excluded subjects with diabetes and physical disabilities such as cardiovascular disease, infectious disease, and musculoskeletal disorders. The study protocol was registered in the UMIN Clinical Trials Registry (Registration No. UMIN000025661) and approved by the Medical Ethics Committee of the National Center for Global Health and Medicine (Reference No. NCGM-G-002161) on 27 March 2017, and all study subjects provided written informed consent prior to participation in this study. The study was performed in accordance with the Declaration of Helsinki.

\subsection{Study Protocol}

\section{Randomization}

Randomization was applied using simple randomization with sex stratification. An independent researcher randomly allocated the subjects to the control and intervention groups at a 1:1 ratio using computer-generated random numbers.

Day 0

We measured $40-50 \%$ of the 1-RM for bench press, leg extension, and leg flexion exercises in each subject in the LST group. We instructed the subjects on how to perform LST, and they were able to practice the training movements before the study.

Day 1

Fasting subjects were fitted with a CGMS device and a triaxial accelerometer at 8:00 a.m. and took Torelan G (75 g glucose solution; $300 \mathrm{kcal}$ per bottle; A Y pharmaceutical Co., Ltd., Tokyo, Japan) immediately thereafter. Subjects in the LST group performed the following training program: LST (bench press, leg extension, and leg flexion) with $3 \mathrm{~s}$ for eccentric and concentric actions, $1 \mathrm{~s}$ pause, and no relaxation phase, for $40 \mathrm{~min}$ from 10:00 a.m. They performed 3 sets of 10 repetitions at an intensity of $40-50 \%$ of their 1-RM with intervals of $1 \mathrm{~min}$. Experienced physiotherapists supervised the subjects to ensure 
that they performed the training movements correctly. On the contrary, subjects in the control group were instructed to perform daily activities as usual without engaging in volitional exercise. Subjects in both groups took standard meals (CalorieMate; $400 \mathrm{kcal}$ per 4 block, $8.7 \mathrm{~g}$ of protein, $22.4 \mathrm{~g}$ of fat, $41.7 \mathrm{~g}$ of carbohydrates; Otsuka Pharmaceutical Co., Ltd., Tokyo, Japan) at 12:00 p.m. and 6:00 p.m., respectively. According to the Japanese dietary reference intakes [16], male subjects took 8 blocks each and female subjects took 6 blocks each at 12:00 p.m. and 6:00 p.m., respectively. Calorie intake was adjusted to $1900 \mathrm{kcal} /$ day in men and $1500 \mathrm{kcal} /$ day in women. Subjects did not consume any food or drink except for the standard meals, water, and green tea.

Day 2

We removed the subjects' CGMS devices and triaxial accelerometers at 8:00 a.m. We checked whether adverse events had occurred and that the devices had worked correctly. The results of a one-time test were used for the analysis. Figure 1 shows a flow chart of the subject recruitment, randomization, and study procedure.

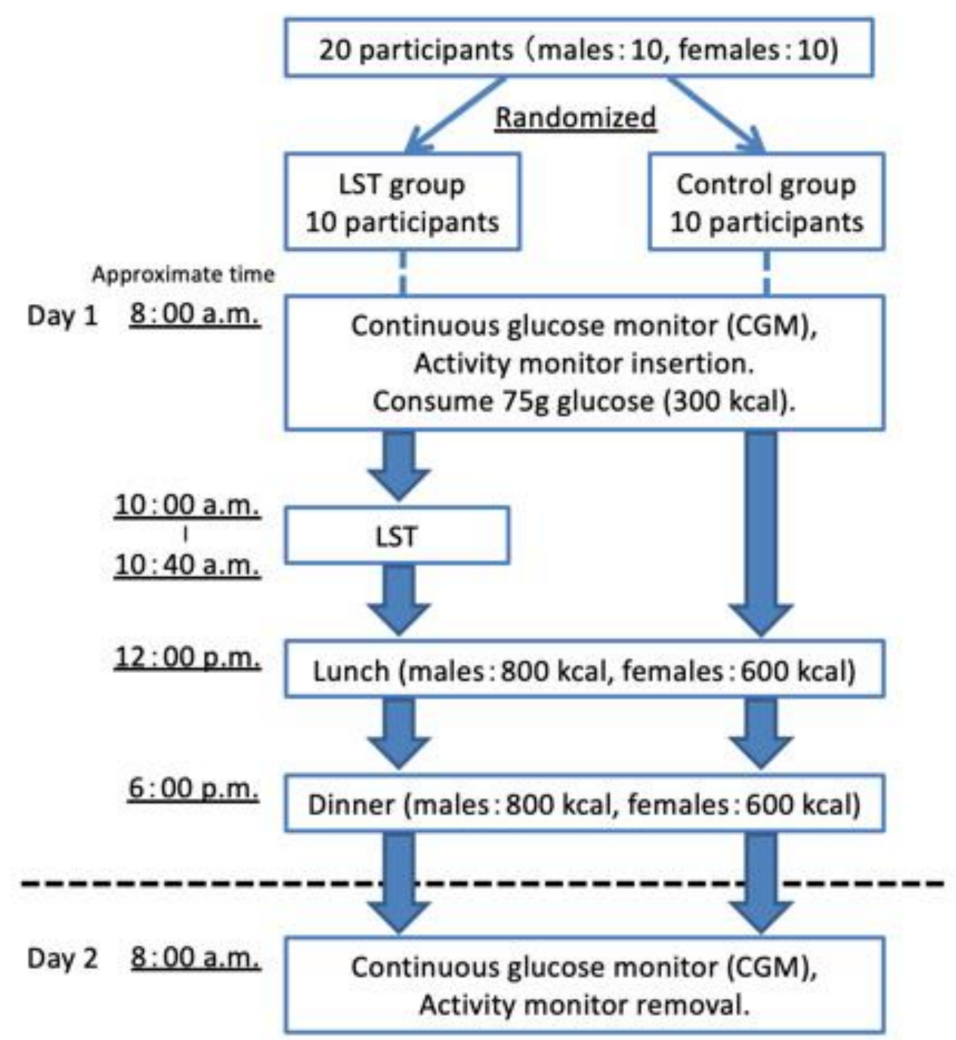

Figure 1. A flow chart of the subject recruitment, randomization, and study procedure. LST, lowintensity resistance exercise with slow movements and tonic force generation.

\subsection{Continuous Glucose Monitoring System}

The primary endpoints of this trial were GV measured by CGMS such as mean glucose levels, standard deviation (SD) values of $24 \mathrm{~h}$ glucose levels, the mean amplitude of glucose excursion (MAGE) [20], the M-value [21], the $24 \mathrm{~h}$ area under the curve (AUC) of glucose, and time spent in hypoglycemia and hyperglycemia. In addition, we evaluated clinical parameters, including fasting glucose levels and glucose levels at 1 and $2 \mathrm{~h}$ after the $75 \mathrm{~g}$ oral glucose tolerance test. We evaluated GV using CGMSR iPro2 ${ }^{\mathrm{TM}}$ (Medtronic, Inc., Northridge, PA, USA) for $24 \mathrm{~h}$. The device was inserted into the abdominal wall, and interstitial glucose levels were recorded every $5 \mathrm{~min}$. Blood glucose levels were also measured from a finger using a glucometer Medisafe Mini GR-102 (TERUMO, Inc., Shibuya, Tokyo, Japan) seven times a day in order to calibrate the interstitial glucose levels measured 
by the CGM device. The M-value is an index used to evaluate GV, as well as the quality of the glycemic control [22]. In the $24 \mathrm{~h}$ AUC analysis, the area between the glucose level of 0 $\mathrm{mg} / \mathrm{dL}$ and the $24 \mathrm{~h}$ glucose curve was determined, and the AUC was calculated using the trapezoidal rule. The M-value was calculated using the following equation [21]:

$$
\mathrm{M}_{\mathrm{BS}}^{\mathrm{BS}}=\left|10 \times \log \frac{\mathrm{BS}}{120}\right|^{3} .
$$

\subsection{Physical Activity Assessment}

The secondary endpoint of this trial was daily physical activity measured using a triaxial accelerometer. Daily physical activity was measured using a triaxial accelerometer (Active Style Pro HJA-750C, Omron Co., Ltd., Kyoto, Japan). The method for physical activity assessment has been described in detail elsewhere $[23,24]$. Subjects were asked to wear the accelerometer, except under specific circumstances such as sleeping, bathing, and during aquatic activities, in accordance with the manufacturer's instructions. Activity data were stored on a minute-by-minute basis and were downloaded onto a personal computer before analysis. The basal metabolic rate (BMR) was estimated from the following multiple regression equation, including age, sex, height, and ideal body weight (IBW) as variables:

$\operatorname{BMR}(\mathrm{kcal} /$ day $)=(0.1283+(0.0481 \times \mathrm{IBW}(\mathrm{kg})+0.0234 \times$ height $(\mathrm{cm})-0.0138 \times$ age $($ year $)-0.5473 \times$ sex coefficient $) \times 293$

The sex coefficient was 1 for men and 2 for women [25].

The total energy expenditure (TEE) was calculated with a manufactured regression equation using METs assessed by the triaxial accelerometer [24]. The physical activity level (PAL) was calculated via the following equation [26]:

$$
\mathrm{PAL}=\mathrm{TEE} / \mathrm{BMR}
$$

\subsection{Statistical Analysis}

Statistical analyses were performed using SPSS version 24 (IBM Co., Ltd., Chicago, $\mathrm{IL}, \mathrm{USA}$ ). All values are expressed as the mean \pm standard deviation. The KolmogorovSmirnov test was performed to assess the normal distribution. Student's $t$-tests (if normal data distribution) and Mann-Whitney $U$-tests (if non-normal data distribution) were performed to examine the differences in clinical parameters between groups. A two-way ANOVA (time $\times$ group) was applied for comparing the time courses of the $75 \mathrm{~g}$ oral glucose tolerance test (OGTT) in the LST and control groups. The Wilcoxon signed-rank test was performed to evaluate the changes in parameters during the study period. In addition, $p$-values of $<0.05$, determined by performing a two-sided test, were considered to be statistically significant.

\section{Results}

\subsection{Characteristics of the Study Subjects}

Table 1 shows the descriptive characteristics of the study subjects. There were no significant differences in age, height, weight, or body mass index (BMI) between the LST and control groups. Table 2 shows the results of OGTT in the LST and control groups. No significant interaction was observed in time $\times$ group. Table 3 shows the CGMS of the primary endpoints and physical activity data of the secondary endpoint for the study subjects. No significant differences were observed between the groups. In addition, the $75 \mathrm{~g}$ OGTT showed that all subjects had normal glucose tolerance. 
Table 1. Descriptive characteristics of the participants in the LST and control groups.

\begin{tabular}{|c|c|c|c|c|}
\hline & (Index) & LST Group & Control Group & $p$-Value \\
\hline Participants & & 10 & 10 & \\
\hline Males & & 5 & 5 & \\
\hline Females & & 5 & 5 & \\
\hline $\mathrm{Age}^{+}$ & $\begin{array}{l}\text { (year) } \\
\text { (range) }\end{array}$ & $\begin{array}{c}28.6 \pm 3.9 \\
22-34\end{array}$ & $\begin{array}{c}27.2 \pm 4.21 \\
23-36\end{array}$ & 0.449 \\
\hline Height $^{+}$ & $\begin{array}{l}(\mathrm{cm}) \\
\text { (range) }\end{array}$ & $\begin{array}{c}163.3 \pm 12.3 \\
149.4-177.5\end{array}$ & $\begin{array}{l}167.4 \pm 8.9 \\
156.9-181.0\end{array}$ & 0.408 \\
\hline Weight $^{+}$ & $\begin{array}{c}(\mathrm{kg}) \\
\text { (range) }\end{array}$ & $\begin{array}{c}60.8 \pm 15.6 \\
44.5-93.0\end{array}$ & $\begin{array}{c}59.6 \pm 10.8 \\
41.0-79.0\end{array}$ & 0.841 \\
\hline $\mathrm{BMI}^{\dagger}$ & $\begin{array}{c}\left(\mathrm{kg} / \mathrm{m}^{2}\right) \\
\text { (range) }\end{array}$ & $\begin{array}{c}22.5 \pm 3.3 \\
19.0-31.1\end{array}$ & $\begin{array}{c}21.1 \pm 2.6 \\
16.0-24.1\end{array}$ & 0.331 \\
\hline
\end{tabular}

Data are displayed as the mean \pm standard deviation (SD). ${ }^{\dagger} t$-test. LST, low-intensity resistance exercises with slow movements and tonic force generation; BMI, body mass index.

Table 2. The results of the $75 \mathrm{~g}$ oral glucose tolerance test (OGTT) in the LST and control groups.

\begin{tabular}{|c|c|c|c|c|c|c|c|c|c|}
\hline & \multirow{2}{*}{ (Index) } & \multirow{2}{*}{ LST Group } & \multirow{2}{*}{ Control Group } & \multicolumn{2}{|c|}{ Group $\times$ Time } & \multicolumn{2}{|c|}{ Group } & \multicolumn{2}{|c|}{ Time } \\
\hline & & & & $F$ & $p$-Value & $F$ & $p$-Value & $F$ & $p$-Value \\
\hline & & & & 0.152 & 0.860 & 0.053 & 0.820 & 17.477 & $<0.001$ \\
\hline $\begin{array}{l}\text { Glucose before } \\
\text { measurement }\end{array}$ & $(\mathrm{mg} / \mathrm{dL})$ & $94.7 \pm 6.2$ & $96.5 \pm 12.1$ & & & & & & \\
\hline OGTT $1 \mathrm{~h}$ & $(\mathrm{mg} / \mathrm{dL})$ & $140.7 \pm 50.8$ & $134.7 \pm 28.7$ & & & & & & \\
\hline OGTT $2 \mathrm{~h}$ & $(\mathrm{mg} / \mathrm{dL})$ & $117.2 \pm 30.6$ & $114.3 \pm 25.4$ & & & & & & \\
\hline
\end{tabular}

Data are displayed as mean \pm standard deviation (SD). LST, low-intensity resistance exercises with slow movements and tonic force generation.

Table 3. A comparison between the LST and control groups.

\begin{tabular}{|c|c|c|c|c|}
\hline & (Index) & LST Group & Control Group & $p$-Value \\
\hline \multicolumn{5}{|l|}{ CGMS data } \\
\hline OGTT $1 \mathrm{~h}$ baseline ${ }^{+}$ & $(\mathrm{mg} / \mathrm{dL})$ & $46.0 \pm 49.1$ & $38.2 \pm 27.0$ & 0.665 \\
\hline OGTT $2 \mathrm{~h}$ baseline $^{+}$ & $(\mathrm{mg} / \mathrm{dL})$ & $22.5 \pm 28.1$ & $17.8 \pm 26.5$ & 0.705 \\
\hline $24 \mathrm{~h}$ average glucose levels ${ }^{+}$ & $(\mathrm{mg} / \mathrm{dL})$ & $93.8 \pm 9.8$ & $99.0 \pm 9.9$ & 0.259 \\
\hline Glucose $\mathrm{SD}^{+}$ & $(\mathrm{mg} / \mathrm{dL})$ & $19.5 \pm 7.9$ & $15.9 \pm 5.6$ & 0.262 \\
\hline High blood sugar integration time $(>140 \mathrm{mg} / \mathrm{dL}) \ddagger$ & $(\%)$ & $0.8 \pm 1.6$ & $0.1 \pm 0.3$ & 0.684 \\
\hline Low blood sugar integration time $(<70 \mathrm{mg} / \mathrm{dL}) \ddagger$ & $(\%)$ & $11.0 \pm 12.8$ & $4.9 \pm 12.8$ & 0.481 \\
\hline Range of the target $(70 \sim 140 \mathrm{mg} / \mathrm{dL}) \ddagger$ & $(\%)$ & $88.2 \pm 12.5$ & $95.0 \pm 12.7$ & 0.353 \\
\hline Total area under the curve ${ }^{\dagger}$ & & $128,797.0 \pm 13,510.7$ & $135,860.8 \pm 13,425.0$ & 0.256 \\
\hline Area under the curve $>140 \mathrm{mg} / \mathrm{dL} \ddagger$ & & $371.8 \pm 784.6$ & $11.0 \pm 34.8$ & 0.684 \\
\hline Area under the curve $<70 \mathrm{mg} / \mathrm{dL} \ddagger$ & & $1269.5 \pm 1623.1$ & $604.0 \pm 1798.5$ & 0.353 \\
\hline Mean amplitude of glycemic excursions $\ddagger$ & $(\mathrm{mg} / \mathrm{dL})$ & $39.5 \pm 13.3$ & $48.1 \pm 39.0$ & 0.579 \\
\hline M-value $120^{\dagger}$ & & $5.3 \pm 3.4$ & $2.9 \pm 3.7$ & 0.152 \\
\hline M-value $100 \ddagger$ & & $2.1 \pm 1.4$ & $1.1 \pm 1.5$ & 0.190 \\
\hline \multicolumn{5}{|l|}{ Physical activity } \\
\hline Basal metabolic rate ${ }^{\dagger}$ & (kcal) & $1346.8 \pm 292.0$ & $1361.6 \pm 219.4$ & 0.899 \\
\hline Total energy expenditure ${ }^{+}$ & (kcal) & $3982.5 \pm 945.4$ & $4316.5 \pm 974.5$ & 0.447 \\
\hline Walking $^{+}$ & & $348.5 \pm 204.7$ & $304.9 \pm 169.0$ & 0.630 \\
\hline Daily living activities ${ }^{\dagger}$ & (METs) & $491.8 \pm 178.7$ & $505.7 \pm 92.4$ & 0.830 \\
\hline Physical activities (walking and daily activities) ${ }^{\dagger}$ & (METs) & $840.3 \pm 341.4$ & $810.6 \pm 231.7$ & 0.822 \\
\hline Number of steps ${ }^{+}$ & (steps) & $12,281.2 \pm 6755.9$ & $10,329.3 \pm 5303.2$ & 0.482 \\
\hline Physical activity level $\ddagger$ & & $3.0 \pm 0.2$ & $3.2 \pm 0.5$ & 0.579 \\
\hline
\end{tabular}

Data are displayed as mean \pm standard deviation (SD). ${ }^{\dagger} t$-test; ${ }^{\ddagger}$ Mann-Whitney $U$-test. LST, low-intensity resistance exercises with slow movements and tonic force generation; CGMS, continuous glucose monitoring system; OGTT, $75 \mathrm{~g}$ oral glucose tolerance test. 


\subsection{Comparison between Pre-and Post-LST}

Table 4 and Figure S1 show a comparison of the pre-LST (10:00-10:40 a.m.) and post-LST (10:40-11:40 a.m.) physiological measurements, which are the primary endpoints. In the LST group, the mean glucose levels decreased and the AUC increased $1 \mathrm{~h}$ after the intervention. Furthermore, the SD significantly decreased $1 \mathrm{~h}$ after the intervention. Conversely, in the control group, the mean glucose levels decreased, and the AUC increased over the time same period; however, the M-value significantly increased at the same time as the LST intervention. 
Table 4. A comparison of pre-LST (10:00-10:40 a.m.) and post-LST (10:40-11:40 a.m.) physiological measurements.

\begin{tabular}{|c|c|c|c|c|c|c|c|}
\hline & \multirow{2}{*}{ (Index) } & \multicolumn{3}{|c|}{ LST Group } & \multicolumn{3}{|c|}{ Control Group } \\
\hline & & Pre & Post & $p$-Value & Pre & Post & $p$-Value \\
\hline Average glucose levels & $(\mathrm{mg} / \mathrm{dL})$ & $135.3 \pm 41.9$ & $97.0 \pm 19.7$ & 0.007 & $124.1 \pm 16.2$ & $91.8 \pm 10.4$ & 0.005 \\
\hline Glucose SD & $(\mathrm{mg} / \mathrm{dL})$ & $11.8 \pm 7.0$ & $6.0 \pm 4.4$ & 0.022 & $9.0 \pm 4.9$ & $6.6 \pm 4.7$ & 0.114 \\
\hline In target range $(70 \sim 140 \mathrm{mg} / \mathrm{dL})$ & $(\%)$ & $69.2 \pm 47.8$ & $93.3 \pm 21.1$ & 0.066 & $76.7 \pm 37.6$ & $99.2 \pm 2.6$ & 0.068 \\
\hline High blood sugar frequency $(>140 \mathrm{mg} / \mathrm{dL})$ & (times/day) & $4.1 \pm 6.2$ & $0.9 \pm 2.8$ & 0.066 & $1.8 \pm 3.6$ & $0 \pm 0$ & 0.109 \\
\hline Low blood sugar frequency $(<70 \mathrm{mg} / \mathrm{dL})$ & (times/day) & $0 \pm 0$ & $0 \pm 0$ & 1.000 & $0 \pm 0$ & $0.1 \pm 0.3$ & 0.317 \\
\hline Total area under the curve & & $8149.8 \pm 2549.4$ & $5864.8 \pm 1183.9$ & 0.007 & $7444.8 \pm 969.8$ & $5490.0 \pm 629.8$ & 0.005 \\
\hline Total area under the curve $>140 \mathrm{mg} / \mathrm{dL}$ & & $946.8 \pm 1775.7$ & $44.8 \pm 141.5$ & 0.068 & $175.8 \pm 379.5$ & $0 \pm 0$ & 0.109 \\
\hline Total area under the curve $<70 \mathrm{mg} / \mathrm{dL}$ & & $0 \pm 0$ & $0 \pm 0$ & 1.000 & $0 \pm 0$ & $0.3 \pm 0.8$ & 0.317 \\
\hline M-value 120 & & $3.5 \pm 6.2$ & $2.7 \pm 2.7$ & 0.575 & $0.4 \pm 0.7$ & $2.7 \pm 2.0$ & 0.017 \\
\hline M-value 100 & & $7.9 \pm 14.1$ & $0.9 \pm 1.3$ & 0.508 & $1.9 \pm 2.9$ & $0.5 \pm 0.4$ & 0.114 \\
\hline
\end{tabular}

Data are displayed as mean \pm standard deviation (SD). LST, low-intensity resistance exercises with slow movements and tonic force generation. 


\section{Discussion}

The present study demonstrated that the indices of GV were improved $1 \mathrm{~h}$ before and after the LST intervention. The M-value is an index of daily GV, which shows the deviation from an ideal glycemic control [21,27]. The M-value is a useful clinical parameter that can measure not only GV, but also the quality of the glycemic control [22]. The M-value did not increase in the LST group, whereas it increased in the control group in the same time period that the LST group underwent training. On the contrary, the SD decreased in the LST group, whereas it did not decrease in the control group. The SD value of $24 \mathrm{~h}$ glucose levels is a strong independent risk factor of mortality in critically ill patients [28-31]. The findings of this study suggest that LST has a beneficial effect on short-term GV in healthy individuals. To the best of our knowledge, this is the first study to show the effect of LST on GV using CGMS.

Although the underlying mechanism by which resistance training improves GV is not yet fully understood, the following two mechanisms have been proposed in accordance with the current evidence. First, increased growth hormone and catecholamine levels due to resistance training stimulate lipolysis and glycogenolysis, which may lead to stable glycemic control [32,33]. Second, rapid decreases in glucose levels after exercise are suppressed by gluconeogenesis due to increased lactic acid levels when performing resistance training [34]. LST is a low-intensity resistance training exercise; however, sustained muscular contraction with slow movement restricts muscle blood flow, decreases oxygen delivery to the contracting muscles, and results in the elevation of blood lactate and growth hormone concentrations after training [35]. Moreover, Tanimoto et al. [13] showed that LST can lead to a comparable increase in lactic acid of that caused by high-intensity (approximately $80 \%$ of 1-RM) exercise training in young men [13]. These endocrine changes may contribute to the improvement of GV.

There were no differences in age, gender ratio, anthropometric parameters, dietary intake, or physical activity between the LST and control groups. There was also no change in physical activity before and after the intervention in either group. Therefore, potential confounding factors such as diet and physical activity appeared to have no influence on GV in this study. However, a few limitations need to be addressed. First, we cannot claim that LST has a favorable effect on GV in patients with diabetes because all study subjects were healthy, young individuals. However, muscle mass declines at a rate of 3-8\% every 10 years after the age of 30 [36], and resistance training is an effective strategy for middle-aged and older individuals to counteract age-related declines in muscle mass and insulin sensitivity and to prevent and manage type 2 diabetes [37]. LST may exhibit more beneficial effects on GV in patients with diabetes. Further studies in older patients with diabetes are warranted. Second, the chronic effect of LST on long-term GV or glycemic control is unknown. Third, we did not obtain dietary recall data or physical activity data from the study participants at baseline. Therefore, there may be potential differences in dietary intake and physical activity between groups prior to the study. However, we suggest that physical activity and dietary intake before the study period do not affect the results because the study subjects had a standardized diet during the study period, and no difference in physical activity measured by a triaxial accelerometer between the control group and the intervention group was observed. Despite these limitations, we demonstrated that LST is effective for improving short-term GV. High-intensity resistance exercise increases blood pressure due to the Valsalva maneuver. However, low-intensity resistance exercise such as LST that is equivalent to $30-50 \%$ 1-RM does not increase blood pressure in healthy individuals [38]. Moreover, LST is a safe and effective intervention approach to treat obesity and type 2 diabetes [18]. In conclusion, the findings of this study suggest that LST improves short-term GV in healthy subjects. These promising results may also be useful for the development of practical exercise therapy that aims to improve GV in patients with diabetes. 
Supplementary Materials: The following are available online at https:/ / www.mdpi.com/2076-3417/ 11/4/1536/s1, Figure S1: A comparison of pre-LST (10:00-10:40 a.m.) and post-LST (10:40-11:40 a.m.) physiological measurements.

Author Contributions: Conceptualization, methodology, formal analysis, investigation, data curation, and writing, T.S. and H.H.; analysis and investigation, A.K. and Y.W.; review and editing and supervision, H.Y. All authors have read and agreed to the published version of the manuscript.

Funding: This research received no external funding.

Institutional Review Board Statement: The study was conducted according to the guidelines of the Declaration of Helsinki, and approved by the Medical Ethics Committee of the National Center for Global Health and Medicine (Reference No. NCGM-G-002161).

Informed Consent Statement: Informed consent was obtained from all subjects involved in the study.

Data Availability Statement: The data that support the findings of this study are available from the corresponding author on reasonable request.

Acknowledgments: The authors appreciate the support of the clinical research coordinators at the Clinical Research Center, National Center for Global Health and Medicine Kohnodai Hospital, for their technical help.

Conflicts of Interest: The authors declare no conflict of interest.

\section{References}

1. Monnier, L.; Mas, E.; Ginet, C.; Michel, F.; Villon, L.; Cristol, J.P.; Colette, C. Activation of Oxidative Stress by Acute Glucose Fluctuations Compared With Sustained Chronic Hyperglycemia in Patients With Type 2 Diabetes. JAMA 2006, 295, 1681-1687. [CrossRef] [PubMed]

2. Abbatecola, A.M.; Rizzo, M.R.; Barbieri, M.; Grella, R.; Arciello, A.; Laieta, M.T.; Acampora, R.; Passariello, N.; Cacciapuoti, F.; Paolisso, G. Postprandial plasma glucose excursions and cognitive functioning in aged type 2 diabetics. Neurology 2006, 67, 235-240. [CrossRef] [PubMed]

3. Xu, F.; Zhao, L.H.; Su, J.B.; Chen, T.; Wang, X.Q.; Chen, J.F.; Wu, G.; Jin, Y.; Wang, X.H. The relationship between glycemic variability and diabetic peripheral neuropathy in type 2 diabetes with well-controlled HbA1c. Diabetol. Metab. Syndr. 2014, 6, 139. [CrossRef]

4. Hsu, C.R.; Chen, Y.T.; Sheu, W.H. Glycemic variability and diabetes retinopathy: A missing link. J. Diabetes Complicat. 2015, 29, 302-306. [CrossRef]

5. Torimoto, K.; Okada, Y.; Mori, H.; Tanaka, Y. Relationship between fluctuations in glucose levels measured by continuous glucose monitoring and vascular endothelial dysfunction in type 2 diabetes mellitus. Cardiovasc. Diabetol. 2013, 12. [CrossRef] [PubMed]

6. Hanefeld, M.; Cagatay, M.; Petrowitsch, T.; Neuser, D.; Petzinna, D.; Rupp, M. Acarbose reduces the risk for myocardial infarction in type 2 diabetic patients: Meta-analysis of seven long-term studies. Eur. Heart J. 2004, 25, 10-16. [CrossRef]

7. Schnell, O.; Barnard, K.; Bergenstal, R.; Bosi, E.; Garg, S.; Guerci, B.; Haak, T.; Hirsch, I.B.; Ji, L.; Joshi, S.R.; et al. Role of Continuous Glucose Monitoring in Clinical Trials: Recommendations on Reporting. Diabetes Technol. Ther. 2017, 19, 391-399. [CrossRef]

8. Yardley, J.E.; Kenny, G.P.; Perkins, B.A.; Riddell, M.C.; Balaa, N.; Malcolm, J.; Boulay, P.; Khandwala, F.; Sigal, R.J. Resistance versus aerobic exercise: Acute effects on glycemia in type 1 diabetes. Diabetes Care 2013, 36, 537-542. [CrossRef] [PubMed]

9. Cruz, L.; Teixeira-Araujo, A.A.; Passos Andrade, K.T.; Rocha, T.; Puga, G.M.; Moreira, S.R. Low-Intensity Resistance Exercise Reduces Hyperglycemia and Enhances Glucose Control Over a 24-Hour Period in Women With Type 2 Diabetes. J. Strength Cond. Res. 2019, 33, 2826-2835. [CrossRef]

10. McDonagh, M.J.; Davies, C.T. Adaptive response of mammalian skeletal muscle to exercise with high loads. Eur. J. Appl. Physiol. Occup. Physiol. 1984, 52, 139-155. [CrossRef]

11. Fleck, S.J. Cardiovascular adaptations to resistance training. Med. Sci. Sports Exerc. 1988, 20, S146-S151. [CrossRef] [PubMed]

12. MacDougall, J.D.; Tuxen, D.; Sale, D.G.; Moroz, J.R.; Sutton, J.R. Arterial blood pressure response to heavy resistance exercise. J. Appl. Physiol. 1985, 58, 785-790. [CrossRef]

13. Tanimoto, M.; Ishii, N. Effects of low-intensity resistance exercise with slow movement and tonic force generation on muscular function in young men. J. Appl. Physiol. 2006, 100, 1150-1157. [CrossRef] [PubMed]

14. Burd, N.A.; Andrews, R.J.; West, D.W.; Little, J.P.; Cochran, A.J.; Hector, A.J.; Cashaback, J.G.; Gibala, M.J.; Potvin, J.R.; Baker, S.K.; et al. Muscle time under tension during resistance exercise stimulates differential muscle protein sub-fractional synthetic responses in men. J. Physiol. 2012, 590, 351-362. [CrossRef] [PubMed]

15. Watanabe, Y.; Tanimoto, M.; Ohgane, A.; Sanada, K.; Miyachi, M.; Ishii, N. Increased muscle size and strength from slowmovement, low-intensity resistance exercise and tonic force generation. J. Aging Phys. Act. 2013, 21, 71-84. [CrossRef] 
16. Kanda, K.; Yoda, T.; Suzuki, H.; Okabe, Y.; Mori, Y.; Yamasaki, K.; Kitano, H.; Kanda, A.; Hirao, T. Effects of low-intensity bodyweight training with slow movement on motor function in frail elderly patients: A prospective observational study. Environ. Health Prev. Med. 2018, 23, 4. [CrossRef] [PubMed]

17. MacDougall, J.D.; McKelvie, R.S.; Moroz, D.E.; Sale, D.G.; McCartney, N.; Buick, F. Factors affecting blood pressure during heavy weight lifting and static contractions. J. Appl. Physiol. 1992, 73, 1590-1597. [CrossRef]

18. Hamasaki, H.; Kawashima, Y.; Tamada, Y.; Furuta, M.; Katsuyama, H.; Sako, A.; Yanai, H. Associations of Low-Intensity Resistance Training with Body Composition and Lipid Profile in Obese Patients with Type 2 Diabetes. PLoS ONE 2015, 10, e0132959. [CrossRef]

19. Bianchi, L.; Volpato, S. Muscle dysfunction in type 2 diabetes: A major threat to patient's mobility and independence. Acta Diabetol. 2016, 53, 879-889. [CrossRef]

20. Service, F.J.; Molnar, G.D.; Rosevear, J.W.; Ackerman, E.; Gatewood, L.C.; Taylor, W.F. Mean amplitude of glycemic excursions, a measure of diabetic instability. Diabetes 1970, 19, 644-655. [CrossRef]

21. Schilichtkrull, J.; Munck, O.; Jersild, M. The M-Value, an Index of Blood-sugar Control in Diabetics. Acta Med. Scand. 1965, 177, 95-102. [CrossRef] [PubMed]

22. David, M.D. The Challenges of Measuring Glycemic Variability. J. Diabetes Sci. Technol. 2012, 712-715. [CrossRef]

23. Oshima, Y.; Kawaguchi, K.; Tanaka, S.; Ohkawara, K.; Hikihara, Y.; Ishikawa-Takata, K.; Tabata, I. Classifying household and locomotive activities using a triaxial accelerometer. Gait Posture 2010, 31, 370-374. [CrossRef] [PubMed]

24. Ohkawara, K.; Oshima, Y.; Hikihara, Y.; Ishikawa-Takata, K.; Tabata, I.; Tanaka, S. Real-time estimation of daily physical activity intensity by a triaxial accelerometer and a gravity-removal classification algorithm. Br. J. Nutr. 2011, 105, 1681-1691. [CrossRef]

25. Ganpule, A.A.; Tanaka, S.; Ishikawa-Takata, K.; Tabata, I. Interindividual variability in sleeping metabolic rate in Japanese subjects. Eur. J. Clin. Nutr. 2007, 61, 1256-1261. [CrossRef]

26. WHO. Energy and Protein Requirements. In Report of a Joint FAO/WHO/UNU Expert Consultation; World Health Organization Technical Report Series; WHO: Geneva, Switzerland, 1985; Volume 724, pp. 1-206.

27. Bando, H.; Ebe, K.; Muneta, T.; Bando, M.; Yonei, Y. Effect of low carbohydrate diet on type 2 diabetic patients and usefulness M-value. Diabetes Res. Open 2017, 3, 9-16. [CrossRef]

28. Krinsley, J.S. Glycemic variability: A strong independent predictor of mortality in critically ill patients. Crit. Care Med. 2008, 36, 3008-3013. [CrossRef]

29. Egi, M.; Bellomo, R.; Stachowski, E.; French, C.J.; Hart, G. Variability of blood glucose concentration and short-term mortality in critically ill patients. Anesthesiology 2006, 105, 244-252. [CrossRef]

30. Matsutani, D.; Sakamoto, M.; Iuchi, H.; Minato, S.; Suzuki, H.; Kayama, Y.; Takeda, N.; Horiuchi, R.; Utsunomiya, K. Glycemic variability in continuous glucose monitoring is inversely associated with baroreflex sensitivity in type 2 diabetes: A preliminary report. Cardiovasc. Diabetol. 2018, 17, 36. [CrossRef] [PubMed]

31. Bragd, J.; Adamson, U.; Bäcklund, L.B.; Lins, P.E.; Moberg, E.; Oskarsson, P. Can glycaemic variability, as calculated from blood glucose self-monitoring, predict the development of complications in type 1 diabetes over a decade? Diabetes Metab. 2008, 34, 612-616. [CrossRef] [PubMed]

32. Bussau, V.A.; Ferreira, L.D.; Jones, T.W.; Fournier, P.A. A 10-s sprint performed prior to moderate-intensity exercise prevents early post-exercise fall in glycaemia in individuals with type 1 diabetes. Diabetologia 2007, 50, 1815-1818. [CrossRef]

33. Bussau, V.A.; Ferreira, L.D.; Jones, T.W.; Fournier, P.A. The 10-s maximal sprint: A novel approach to counter an exercise-mediated fall in glycemia in individuals with type 1 diabetes. Diabetes Care 2006, 29, 601-606. [CrossRef] [PubMed]

34. Guelfi, K.J.; Jones, T.W.; Fournier, P.A. The decline in blood glucose levels is less with intermittent high-intensity compared with moderate exercise in individuals with type 1 diabetes. Diabetes Care 2005, 28, 1289-1294. [CrossRef] [PubMed]

35. Tanimoto, M.; Madarame, H.; Ishii, N. Muscle oxygenation and plasma growth hormone consentration during and after resistance exercise: Comparison between "KAATSU" and other types of regimen. Int. J. KAATSU Train. Res. 2005, 1, 51-56. [CrossRef]

36. Percheron, G.; Hogrel, J.Y.; Denot-Ledunois, S.; Fayet, G.; Forette, F.; Baulieu, E.E.; Fardeau, M.; Marini, J.F. Effect of 1-year oral administration of dehydroepiandrosterone to 60- to 80-year-old individuals on muscle function and cross-sectional area: A double-blind placebo-controlled trial. Arch. Intern. Med. 2003, 163, 720-727. [CrossRef]

37. Flack, K.D.; Davy, K.P.; Hulver, M.W.; Winett, R.A.; Frisard, M.I.; Davy, B.M. Aging, resistance training, and diabetes prevention. J. Aging Res. 2010, 127315. [CrossRef] [PubMed]

38. Tanimoto, M.; Sanada, K.; Yamamoto, K.; Kawano, H.; Gando, Y.; Tabata, I.; Ishii, N.; Miyachi, M. Effects of whole-body low-intensity resistance training with slow movement and tonic force generation on muscular size and strength in young men. J. Strength Cond. Res. 2008, 22, 1926-1938. [CrossRef] [PubMed] 